\title{
Sever's Disease: An Underdiagnosed Foot Injury in the Pediatric Emergency Department
}

\author{
Michael Marchick, Henry Young, Mathew F. Ryan \\ Department of Emergency Medicine, Gainesville, FL, USA \\ Email: hyoungii@ufl.edu
}

Received 25 September 2015; accepted 12 December 2015; published 15 December 2015

Copyright ( 2015 by authors and Scientific Research Publishing Inc.

This work is licensed under the Creative Commons Attribution International License (CC BY). http://creativecommons.org/licenses/by/4.0/

(c) (i) Open Access

\begin{abstract}
Sever's disease-also known as calcaneal apophysitis-is a common cause of heel pain in pediatric patients typically aged 7 - 14 years old. Sever's disease can be painful and limit a child's function as well as participation in physical activity. Herein, we described a case of delayed presentation of chronic Sever's disease in a child who had been experiencing heel pain for over one year which worsened substantially when the child began to participate in sports. This is important for the emergency medicine physician because Sever's disease represents an underdiagnosed cause of foot and heel pain in the pediatric patient and may be often missed. We describe the diagnosis and treatment options of Sever's disease as well as associated controversies, e.g., whether activity is indeed the cause of Sever's disease and whether imaging is needed for a diagnosis.
\end{abstract}

\section{Keywords}

Foot Pain, Heel Pain, Pediatric, Sever's Disease

\section{Introduction}

Sever's disease is inflammation of the calcaneal apophysis which can be painful and limit a child's physical activity. It is one of the most common causes of heel pain in pediatric patients [1], often aged 7 - 14 years old and especially in those who are active in high-impact sports such as football, basketball or soccer [2]. Presentation often occurs at the beginning of the sports season when activity is increased above the patient's baseline [3]. The calcaneal apophysis is a cartilaginous growth center where the Achilles tendon inserts. Repeated pull and strain on the calcaneal apophysis during activity are thought to result in the accumulation of microscopic tears in the apophysis which eventually results in localized inflammation and subsequent pain [4]. We presented a case of 
Sever's disease in a male patient which was exacerbated by the child's preference to walk barefoot and ultimately became manifest when the child initiated participation in organized sports. While most cases of Sever's disease were associated with increased activity, our patient complained of heel pain for months, and was seen several times by his primary care physician, all the while walking predominantly shoeless prior to participating in sports. Immediately after he began an athletic program his pain was exacerbated and he was unable to further participate due to pain and discomfort. We describe herein essential keys to the diagnosis and treatment options of Sever's disease. We note that it is important for the emergency medicine physician because the symptoms are prevalent, preventable, treatable, and often overlooked in the pediatric population.

\section{Case Report}

An eleven-year-old male patient presented to the pediatric emergency department (ED) with waxing and waning heel pain for one-year's duration. The patient's father noted the child walked primarily barefoot or in non-supportive shoes (e.g., flip flops) when necessary or required, for example at school. The child presented after his second day of American-football practice complaining of heel pain and associated calf pain and worsened with ambulation.

The child's vital signs were within normal limits and he had no other complaints. He was a well-developed, well-nourished eleven-year old boy. His BMI was within normal limits for his age and he was in the 3rd quartile for his height and weight [5]. On physical exam, the child demonstrated full range of motion bilaterally in his lower extremities including his foot and ankle. Pain was primarily isolated to his left heel and did not involve the ankle or anterior portions of his foot. The patient also had pain on palpation of his Achilles tendon and his calf muscles. An X-ray of the foot was obtained as shown (Figure 1) which revealed calcaneal apophysitis.

The child was discharged with instructions to take anti-inflammatory medication, to wear supportive shoes, and he was given information on proper stretching techniques to prevent further injury and to speed recovery. Upon follow up, he was reported to have followed the recommended treatment regimen with significant improvement of his symptoms and subsequently returned to normal activity.

\section{Discussion}

Sever's disease is an inflammatory condition of the calcaneal apophysis which often presents in children between the ages of 7 and 14 years old. This is because the calcaneal apophysis develops as an independent ossification center which commences around age7 with complete fusion of the ossified center concluding typically by age 14 [4]. The mechanism for Sever diseases is similar to apophysitis of the knee (Osgood-Schlatter disease).

During times of increased child growth and development, the apophyses, which are secondary ossification centers, are prone to injury [6]. Compounding this risk for injury, apophyses serve as sites of muscle-tendon insertion and contain a higher composition of fibrocartilage than epiphyses, and thus are subjected to increased stress (i.e., axial compression). In the developing child, muscles attached to apophyses may cause increased stress and strain (compression and lengthening) and repetitive forceful traction can result in microtrauma to these secondary growth centers [4]. The accumulating result is localized inflammation, pain and swelling often

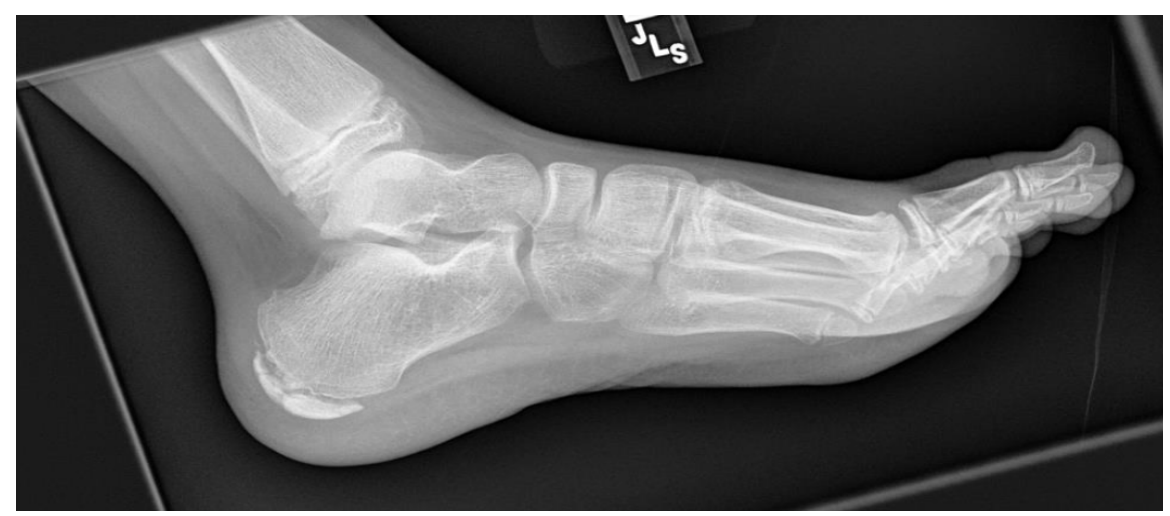

Figure 1. Lateral X-ray of an 11-year-old male patient demonstrating increased lucency of the calcaneal apophysis. 
extending along associated tendinous connections. Chronic inflammation at the bone-cartilage junction can result. Undiagnosed Sever's disease was the cause of the child's chronic pain, and increased activity exacerbated his pain. Note, a prospective study demonstrated Sever's disease is most likely due to forefoot-rearfoot malalignment rather than increased activity [7]. However, while anatomical malalignment may be the underlying cause of the disease, many argue activity can lead to increased pain [1] [2] which results in the patient seeking medical attention.

The presentation of Sever's disease is variable. Typically, the patient may present with a limp and complain of pain during or after activity. Either one or both heels may be affected. The use of plain films for the diagnosis of Sever's disease has been debated. This is because the radiologic findings due to Sever's disease vary broadly between independent observers and between separate readings by the same observer [8]. Accordingly, Sever's disease can best be diagnosed clinically and imaging is not necessary [9]. However, when a pediatric patient presents to the ED complaining of foot pain, the differential diagnosis may include a fracture or dislocation, both of which require imaging. For this reason, we advocate $\mathrm{X}$-rays to assess for potential fractures. Moreover, the benefits of an X-ray of the foot to diagnosis a fracture or dislocation are outweighed by the risks of radiation exposure to a child, which only represents $10-3 \mathrm{mSv}$ (whereas a chest X-ray is $0.02 \mathrm{mSv}$ ) [9].

There is no specific treatment for Sever's disease and symptom management is key for the affected patient. While physical activity is not harmful, the pain may require the child to limit or modify their activity as tolerated. Sport shoes that are comfortable and fit well may lessen the symptoms. The standard treatment of rest, ice, elevation and anti-inflammatory medication is also recommended. Support heel pads and proper warm-up and stretching regiments are also effective before and after activity. The symptoms typically last 6 - 12 months but may persist longer. Note, complete recovery is the norm.

\section{Conclusion}

Sever's disease is a common cause of heel pain in the developing foot of a child. While anatomical malalignment may increase the likelihood of developing Sever's disease, activity is linked to exacerbations of pain and injury. In the ED, we recommend imaging to assess for more severe injuries such as fractures or dislocations. We note that this clinical presentation is important for the emergency medicine physician because the symptoms are prevalent, preventable, treatable, and often overlooked in the pediatric population.

\section{Conflicts of Interest}

The authors declare no conflict of interests.

\section{References}

[1] Kim, C.W., Shea, K. and Chambers, H.G. (1999) Heel Pain in Children. Diagnosis and Treatment. Journal of the American Pediatric Medical Association, 89, 67-74. http://dx.doi.org/10.7547/87507315-89-2-67

[2] Ogden, J.A., Ganey, T.M., Hill, J.D., et al. (2004) Sever's Injury: A Stress Fracture of the Immature Calcaneal Metaphysis. Journal of Pediatric Orthopedics, 24, 488-492. http://dx.doi.org/10.1097/01241398-200409000-00007

[3] Scharfbillig, R., Jones, S. and Scutter, S.D. (2008) Sever's Disease: What Does the Literature Really Tell Us? Journal of the American Podiatric Medical Association, 98, 212-223. http://dx.doi.org/10.7547/0980212

[4] Kannus, P. (1997) Etiology and Pathophysiology of Chronic Tendon Disorders in Sports. Scandinavian Journal of Medicine \& Science in Sports, 7, 78-85. http://dx.doi.org/10.1111/j.1600-0838.1997.tb00123.x

[5] The National Center for Health Statistics in Collaboration with the National Center for Chronic Disease Prevention and Health Promotion. http://www.cdc.gov/growthcharts

[6] Hoang, Q.B. and Mortazavi, M. (2012) Pediatric Overuse Injuries in Sports. Advances in Pediatrics, 59, 359-383. http://dx.doi.org/10.1016/j.yapd.2012.04.005

[7] Scharfbillig, R., Jones, S. and Scutter, S.D. (2011) Sever's Disease: A Prospective Study of Risk Factor. Journal of the American Podiatric Medical Association, 101, 133-145. http://dx.doi.org/10.7547/1010133

[8] Kose, O., Celiktas, M., Yigit, S. and Kisin, B. (2010) Can We Make a Diagnosis with Radiographic Examination Alone in Calcaneal Apophysitis (Sever's Disease)? Journal of Pediatric Orthopaedics B, 19, 396-398. http://dx.doi.org/10.1097/BPB.0b013e32833a5fa7

[9] Wall, B.F. and Hart, D. (1997) Revised Radiation Doses for Typical X-Ray Examinations. The British Journal of Radiology, 70, 437-439. 